\title{
EFFECT OF HALOTHANE ON THE PULMONARY VASCULAR RESPONSE TO HYPOXIA IN DOGS*
}

\author{
Angelica Fargas-Babjak and James B. Forrest
}

INDUCTION of general anaesthesia tends to impair pulmonary gas exchange and to cause a reduction in the partial pressure of oxygen in arterial blood. A number of factors account for this, such as reduction of functional residual volume, abnormal ventilation perfusion ratio $\left(\dot{\mathrm{V}}_{\mathrm{A}} / \dot{\mathrm{Q}}\right)$, closure of airways and micro-atelectasis; ${ }^{1}$ but of these the most important determinant of net gas exchange in the lungs is the relative matching of ventilation and blood flow. ${ }^{2}$ While the distribution of both ventilation and blood flow is governed mainly by gradients of transpleural pressure and hydrostatic vascular pressures, there is some local modification of the distribution of blood flow in hypoxic regions by pulmonary vasoconstriction. Thus, local flow tends to decrease, causing the $\dot{V}_{A} / Q$ ratio to increase and, as Hauge $^{3}$ found in awake subjects, the resulting increased pulmonary vascular resistance (PVR) triggered by alveolar hypoxia causes blood to be redistributed away from poorly ventilated to better ventilated regions. The net result of this response is to minimize arterial oxygen desaturation. When anaesthetized dogs are subjected to alveolar hypoxia, the rise in PRV is inversely and linearly related to arterial oxygen saturation, but the slope of this response varies greatly between animals. ${ }^{4}$

Evidence is accumulating that many inhalational anaesthetics in clinically useful concentrations may attenuate or abolish this response, so potentiating the development and persistence of low $\dot{V}_{\mathrm{A}} / \dot{\mathrm{Q}}$ ratios in regions of the lungs of the anaesthetized subject. ${ }^{5}$

Studies on isolated perfused lungs have shown that halothane and methoxyfluorane reduce this protective response of the pulmonary vascula-

* Supported by the Canadian Medical Research Council, Grant \#MA 5880. Presented in part at the Canadian Anaesthetists' Society Meeting, June 20-23, 1977.

Angelica Fargas-Babjak, M.D., Resident in Anaesthesia and James B. Forrest, M.B., Ch.B., Ph.D., F.F.A.R.C.S., Associate Professor, Departments of Anaesthesia and Medicine. McMaster University Health Sciences Centre, Hamilton. Ontario, Canada L8S 4J9. ture to hypoxia. ${ }^{6,7}$ More recent studies on isolated lung lobes demonstrated even greater inhibition of hypoxic pulmonary vasoconstriction by fluoroxene, and isofluorane. ${ }^{8}$

In intact animals, however, the effect of these halogenated anaesthetics on pulmonary vascular resistance (PVR) during hypoxic breathing is unclear. As indicated above, our previous studies in the $\operatorname{dog}^{4}$ demonstrated great variation between individuals in the PVR response to hypoxia expressed in terms of arterial oxygen saturation, but in any one individual the response was highly significant and reproduceable. Further, a low PVR response resulted in a much greater arterial oxygen desaturation at equivalent levels of inspired oxygen than occurred in animals with high PVR responses. Attenuation of the hypoxic PVR response by inhalational anaesthetics could potentiate arterial oxygen desaturation. It would be useful in these circumstances to be able to predict those individuals at risk from severe arterial oxygen desaturation.

We have therefore measured the PVR responses to hypoxia in intact dogs with and without exposure to halothane and correlated these with arterial oxygen saturation.

\section{Materials AND METHODS}

The experimental design which was used is shown in Figure 1.

Ten adult mongrel dogs (weight range $17-34 \mathrm{~kg}$ ) were anaesthetized with intravenous pentobarbitone $(30 \mathrm{mg} \cdot \mathrm{kg})$, paralyzed with pancuronium $(0.06 \mathrm{mg} \cdot \mathrm{kg})$ intubated with a cuffed tracheal tube and placed in the supine position. Supplemental doses of anaesthetic and muscle relaxant were administered as required to ensure an adequate level of anaesthesia and muscle paralysis during each hypoxic episode.

Ventilation was controlled with intermittent positive pressure ventilation (IPPV) from a Harvard respirator. Tidal volume and frequency were set using the Radford nomogram and held constant throughout the experiment. Catheters were placed in each femoral artery for pressure recording and arterial blood gas sampling and in 


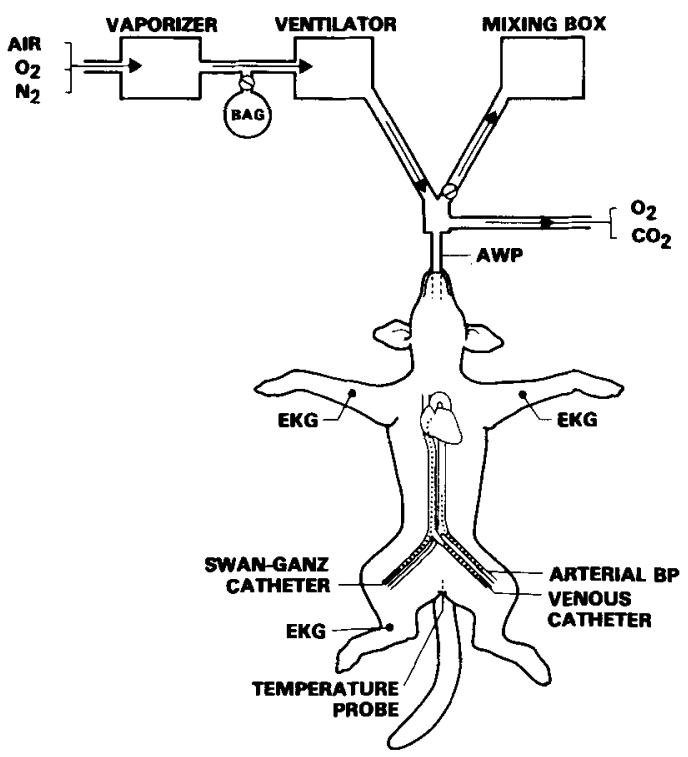

FIgURE 1 Experimental design in mechanically ventilated anaesthetized dogs.

the left femoral vein for administration of drugs and sampling of blood for determination of haemoglobin and haematocrit. A triple lumen thermistor tipped Swan-Ganz catheter was placed through the right femoral vein into the pulmonary artery for measurement of pulmonary artery pressure (Ppa), pulmonary wedge pressure (PWP) and cardiac output ( $\dot{\mathrm{Q}})$ by the thermodilution method using an Edwards cardiac output computer (9510-A). Pulmonary arterial blood was sampled for mixed venous blood gas estimation.

Continuous monitoring of respired concentrations of oxygen and carbon dioxide was made by rapid gas analyzers (Beckman OM-1 102 analyser, LB-2 gas analyzer). Mixed expired carbon dioxide samples were obtained using a mixing box in the expiratory line and were measured at the end of each control and hypoxic period.

Other parameters measured were airway pressure, electrocardiogram and rectal temperature by thermistor probe. All pressures were measured by Statham (P37b) transducers which, together with breath to breath oxygen and carbon dioxide concentrations and electrocardiogram were recorded on Beckman Dynograph (R411) and Hewlett Packard (HP2201) pen recorders. Blood gases were measured in an Instrumentation Laboratory " $\mathrm{pH} /$ gas analyzer" using the microelectrode method. Calibration by tonometry was done throughout each experiment. Calculation of arterial oxygen saturation $\left(\mathrm{Sa}_{2}\right)$ was done using the Rossing and Cain equation for dog blood $^{9}$ as previously described. ${ }^{4}$
Pulmonary vascular resistance (PVR) was calculated from:

$\mathrm{PVR}=(\mathrm{Ppa}-\mathrm{PWP}) / \dot{\mathrm{Q}}$ expressed as

$\mathrm{mmHg} \cdot \min \cdot \mathrm{L}^{-1}$

During an initial 60-minute set-up period, oxygen was added to the inspired air to give an $\mathrm{Sa}_{\mathrm{O}_{2}}$ of more than 98 per cent, and thereafter the same oxygen-air mixture was used during recovery periods, and during halothane exposure.

At the end of this set-up period, baseline values of all parameters were obtained by serial estimation. Hypoxia was then induced by switching to an inspired mixture of oxygen in nitrogen for five minutes, using inspired oxygen concentrations of $8,11,15$, or 20 per cent, followed by a 30 -minute recovery period after each exposure. Hypoxic PVR responses were thus established for each animal, before exposure to halothane.

The animal was then ventilated for 15 minutes with halothane 1.5 per cent and submitted to five minutes of alveolar hypoxia followed by a further 30-minute recovery period breathing the oxygen-air mixture. This sequence was then repeated four times using different levels of hypoxia under halothane anaesthesia.

Control and halothane normoxic values for all parameters refer to those recorded at the end of each recovery period and after 15 minutes of exposure to halothane 1.5 per cent respectively, while hypoxic values refer to those recorded after five minutes of exposure to hypoxia with or without exposure to halothane. In our previous study ${ }^{4}$ on the effects of hypoxia alone, we have shown that all parameters measured reach a plateau in less than four minutes after switching to inspiration of hypoxic oxygen/nitrogen mixture.

Statistical Methods: Data were analysed by Student paired t-tests. Linear regression analysis was done by analysis of variance of paired values. Statistical significance was taken as $P=0.05$ or less.

\section{RESUlts}

\section{Sequential changes in PVR during normoxic breathing}

The effect of repeated exposure to halothane and different levels of hypoxia was examined by comparing successive PVR values at normoxia. Figure 2 shows each of the four consecutive control PVR and three halothane values for each animal with the group means $( \pm 1 S D)$ indicated. Control PVR (open circles) increased progressively so that after the fourth experimental se- 


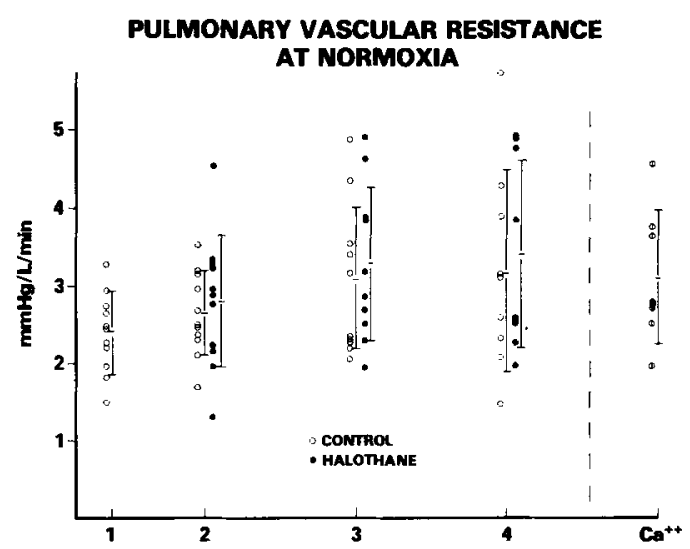

Figure 2 Pulmonary vascular resistance at normoxia after consecutive exposure to $\mathrm{O}_{2}$-air controls (open circles) and to halothane (closed circles). The mean value for all dogs \pm 1 SD is indicated. Measurements after calcium infusion are shown on the right. Mean values are not statistically different at the 5 per cent probability level.

quence it was about 18 per cent above the initial value. A similar increase was found for PVR measured after 15 minutes of halothane exposure (closed circles) at normoxia. At the beginning of each halothane induction. PVR increased by about 6 per cent over the preceding control value, but did not change appreciably thereafter during normoxic breathing. None of these changes are statistically significant, but similar trends occurred in each case.

At the end of each experiment, calcium chloride $(10 \mathrm{mg} \cdot \mathrm{kg})$ was injected intravenously and the PVR response to hypoxia was measured. Increasing extracellular calcium did not alter baseline PVR nor the response to hypoxia.

The sequential changes in mean $\mathrm{Q}$ are shown in Figure 3 for each of four control periods and three halothane exposures at normoxia with mean values $( \pm 1$ SD) indicated. Control cardiac output decreased by 24 per cent throughout the experiment, but this was not statistically significant.

At the end of the first period of halothane exposure at normoxia, $\dot{Q}$ was about 31 per cent less than the preceding control (column 2), but was only 19 per cent less at the end of the third exposure. Only an 8 per cent change occurred in $Q$ between the first and the last exposure. to halothane.

A similar trend was found for pulmonary artery pressure ( $\mathrm{Ppa}$ ) but the magnitude of the change was much less than for $\dot{Q}$. Halothane decreased mean Ppa by 6 per cent on the first and second exposures. After the third halothane exposure mean Ppa increased very slightly by one per cent.

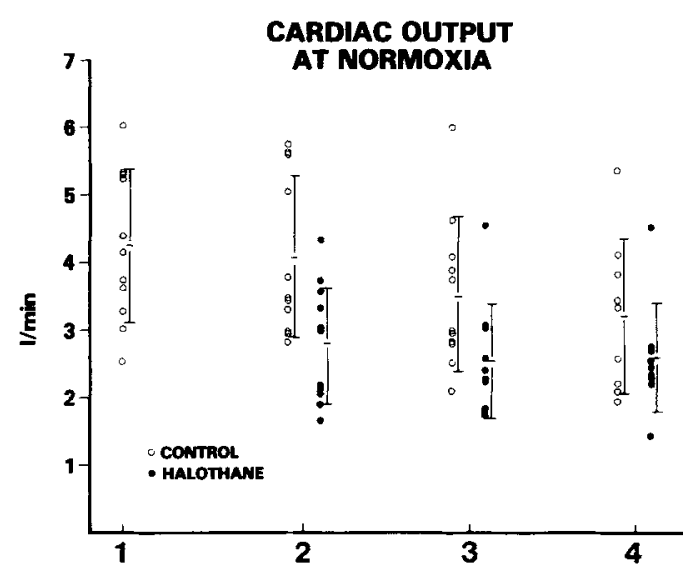

FIgURE 3 Cardiac output at normoxia after consecutive exposures to $\mathrm{O}_{2}$-air controls (open circles) and to halothane (closed circles). The mean value for all dogs \pm 1 SD is indicated. Mean values are not statistically different at the 5 per cent probability level.

While the changes in mean values of PVR, Ppa and $\dot{Q}$ were not statistically significant, the trends quoted above occurred in all dogs. Heart rate, electrocardiogram and airway pressure remained unaltered during normoxic breathing. Hypoxia caused a small increase in heart rate $(\overline{\mathrm{m}} 6 \mathrm{~b} / \mathrm{min})$ at an inspired oxygen of 20 per cent but heart rate was reduced progressively with decreasing inspired oxygen, so that the mean reduction was $11 \mathrm{~b} / \mathrm{min}$ when inspired oxygen was 8 per cent. No arrhythmias were noted. Mean airway pressure increased slightly in all dogs with hypoxia by a mean of one per cent above controls, but this was not statistically significant. Halothane reduced heart rate $(\overline{\mathrm{m}} 8 \mathrm{~b} / \mathrm{min})$ and airway pressure (2 per cent of controls) while halothane plus hypoxia resulted in a further reduction in heart rate ( $\overline{\mathrm{m}} 14 \mathrm{~b} / \mathrm{min}$ compared to controls), but increased airway pressure to equal control values. No arrhythmias were induced by hypoxia during halothane exposure.

Responses of pulmonary vascular resistance to hypoxia

A regression analysis of the PVR response to different levels of hypoxia with and without halothane exposure was done in all animals and is summarized in Table I. The linear slopes of these PVR responses to hypoxia are shown in Figure 4 for each of the 10 dogs, plotted as PVR against $\mathrm{Sa}_{\mathrm{O}_{2}}$. For the sake of clarity, these have been drawn as two groups of five dogs each.

The solid lines labelled with the small letters show the PVR slopes for each animal with hypoxia alone (control hypoxic PVR response) 
TABLE I

Regression ANalysis For PVR/Arterial Oxygen Saturation

\begin{tabular}{lccccccc}
\hline \hline & \multicolumn{3}{c}{ Hypoxia } & & & \multicolumn{3}{c}{ Hypoxia and halothane } \\
\cline { 2 - 4 } \cline { 6 - 8 } Dog & Slope & Intercept & $\mathrm{r}$ & & Slope & Intercept & $\mathrm{r}$ \\
\hline $\mathrm{a}$ & -0.007 & 3.32 & $0.868^{\dagger}$ & & -0.057 & 8.76 & $0.709 \ddagger$ \\
$\mathrm{b}$ & -0.019 & 4.19 & $0.983^{*}$ & & -0.067 & 9.03 & $0.82 \dagger^{\dagger}$ \\
$\mathrm{c}$ & -0.006 & 3.99 & $0.665 \ddagger$ & & -0.056 & 8.63 & $0.904^{*}$ \\
$\mathrm{~d}$ & -0.028 & 4.69 & $0.999^{*}$ & & -0.052 & 7.89 & $0.991^{*}$ \\
$\mathrm{e}$ & -0.003 & 3.27 & $0.998^{*}$ & & -0.071 & 9.49 & $0.956^{*}$ \\
$\mathrm{f}$ & -0.130 & 14.29 & $0.999^{*}$ & & -0.158 & 18.41 & $0.8466^{\dagger}$ \\
$\mathrm{g}$ & -0.102 & 12.10 & $0.990^{*}$ & & -0.140 & 17.06 & $0.785 \dagger$ \\
$\mathrm{h}$ & -0.203 & 21.74 & $0.999^{*}$ & & -0.237 & 25.06 & $0.991^{*}$ \\
$\mathrm{i}$ & -0.006 & 2.08 & $0.898 \dagger$ & & -0.048 & 6.10 & $0.639 \ddagger$ \\
$\mathrm{j}$ & -0.075 & 9.42 & $0.974^{*}$ & & -0.112 & 14.97 & $0.937^{*}$ \\
\hline
\end{tabular}

${ }^{*}$ Significant at $\mathrm{P} \leq 0.001$.

†Significant at $\mathrm{P}<0.01$.

tSignificant at $\mathrm{P}=0.01$.

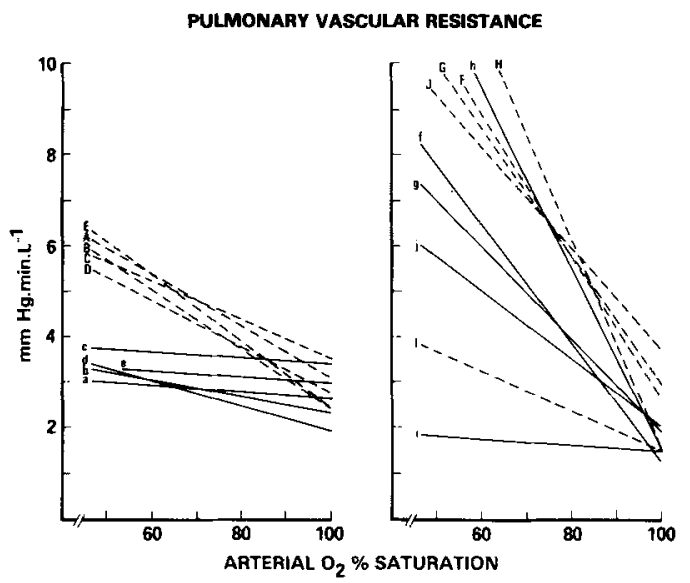

FIGURE 4 Pulmonary vascular resistance against arterial $\mathrm{O}_{2}$ per cent saturation. Solid lines (small letters) are control linear slopes and hatched lines (large letters) are slopes after halothane. Regression values are given in Table I.

while the hatched lines labelled with the corresponding capital letters are the PVR slopes after exposure to halothane. As in our previous study, ${ }^{4}$ the control PVR responses were statistically significant $(P<0.01)$ inverse relationships with $\mathrm{Sid}_{0.2}$ but showed great variability between dogs. The range of slopes was from -0.003 to -0.203 with a mean of -0.058 and a mean correlation coefficient of 0.938 . Those dogs represented on the left panel of Figure 4 (a to e) and including dog " $i$ " on the right panel were low responders whereas dogs "f", "g", "h", and "j" were high responders (right panel in Figure 4).

The slopes of the PVR responses after halothane exposure were also statistically highly significant $(\mathrm{P}<0.01)$ and showed inverse linear relationships with $\mathrm{Sa}_{0_{2}}$, with slopes in the range from -0.012 to -0.237 . The mean slope was -0.096 with a mean correlation coefficient of 0.858 . Halothane increased the absolute values of PVR at all levels of $\mathrm{Sa}_{0_{2}}$ in all $10 \mathrm{dogs}$ but the change in the PVR slope after exposure to halothane was variable. Low responders showed a range in slopes after halothane from -0.048 to -0.071 with a mean of -0.059 and mean correlation coefficient of 0.837 . High responders on the other hand, had slopes after halothane which ranged from -0.112 to -0.237 with a mean of -0.162 and a mean correlation coefficient of 0.890. It is evident from Figure 4 that the low responders (those showing little or no increase in control PVR with hypoxia) increased PVR least after halothane. These dogs also had the most severe arterial desaturation during control hypoxic and halothane exposures. On the other hand, the high responders showed least arterial oxygen desaturation during control hypoxic and halothane exposures. In all cases as a result of increased PVR during halothane exposure, the $\mathrm{Sa}_{\mathrm{O}_{2}}$ was slightly greater at equivalent levels of PVR than with hypoxia alone.

Pulmonary artery pressure increased with hypoxia under halothane anaesthesia but the absolute values of Ppa were lower than with hypoxia alone. Statistically significant inverse linear relationships were found for Ppa against $\mathrm{Sa}_{\mathrm{O}_{2}}$ similar to those described above for PVR, with the exception of one dog "i", where the linear correlation with hypoxia was not significant. This contrasts with a significant correlation between PVR and $\mathrm{Sa}_{\mathrm{O}_{2}}$ in this dog (Table I). 
TABLE II

Regression Analysis of Ppa/Arterial Oxygen Saturation

\begin{tabular}{cccccccc}
\hline \hline & \multicolumn{3}{c}{ Hypoxia } & & & \multicolumn{3}{c}{ Halothane and hypoxia } \\
\cline { 2 - 4 } \cline { 6 - 7 } Dog & Slope & Intercept & $\mathrm{r}$ & & Slope & Intercept & $\mathrm{r}$ \\
\hline a & -0.044 & 17.99 & $0.652 \ddagger$ & & -0.189 & 31.92 & $0.794 \ddagger$ \\
b & -0.101 & 22.22 & $0.979^{*}$ & & -0.262 & 39.36 & $0.944^{*}$ \\
c & -0.039 & 19.64 & $0.998^{*}$ & & -0.126 & 27.76 & $0.950^{*}$ \\
d & -0.132 & 30.43 & $0.992^{*}$ & & -0.232 & 39.46 & $0.969^{*}$ \\
e & -0.031 & 22.93 & $0.996^{*}$ & & -0.240 & 40.18 & $0.882 \dagger$ \\
f & -0.368 & 44.72 & $0.991^{*}$ & & -0.339 & 45.03 & $0.806 \ddagger$ \\
g & -0.354 & 52.23 & $0.996^{*}$ & & -0.218 & 36.89 & $0.807 \ddagger$ \\
h & -0.694 & 77.83 & $0.998^{*}$ & & -0.488 & 56.53 & $0.948^{*}$ \\
i & -0.025 & 12.40 & 0.565 ns & -0.051 & 18.33 & $0.887 \dagger$ \\
j & -0.243 & 38.56 & $0.868 \dagger$ & -0.306 & 43.67 & $0.843 \dagger$ \\
\hline
\end{tabular}

*Significant at $\mathbf{P} \leq 0.001$.

$\uparrow$ Significant at $\mathbf{P}<0.01$.

tSignificant at $\mathrm{P}=0.01$.

PVR responses were significant at $P=0.01$ or less following halothane exposure in all dogs. The regression analysis of these data are summarized in Table II.

The range of slopes for Ppa with $\mathrm{Sa}_{02}$ with hypoxia alone was -0.025 to -0.694 and after halothane was -0.051 to -0.488 . The overall mean slopes for Ppa in control responses and after halothane were -0.199 and -0.238 , giving mean correlation coefficients of 0.910 and 0.887 respectively.

An analysis of variance (ANOVA) was done of control hypoxic PVR and Ppa slopes versus the slopes after halothane exposure to determine whether these were altered in a consistent and predictable manner. The ANOVA showed a highly significant relationship between the control hypoxic slopes for both PVR and for Ppa against the slopes after halothane. These data were also subjected to linear regression analysis and highly significant correlations were found so that the halothane PVR slope $\left(b_{R} H\right)$ was given by:

$$
b_{R} H=0.899 b_{R}-0.048 \text {, }
$$

where $b_{R}$ is the control PVR slope, significant at $\mathrm{P}=\mathbf{0 . 0 0 1}$, and with a correlation coefficient $\mathrm{r}=0.933$.

The above relationship, together with the paired control and halothane slope values, are shown in Figure 5. Clearly if the control PVR response is known, the PVR response following halothane can be predicted with a high degree of accuracy. Similar predictions can be obtained for Ppa from the halothane Ppa slope $\left(b_{p} H\right)$ where $b_{p} H=0.462 b_{p}-0.149,\left(b_{p}\right.$ is the control slope, $r$ $=0.870$ and $\mathrm{P}=0.003$ ).

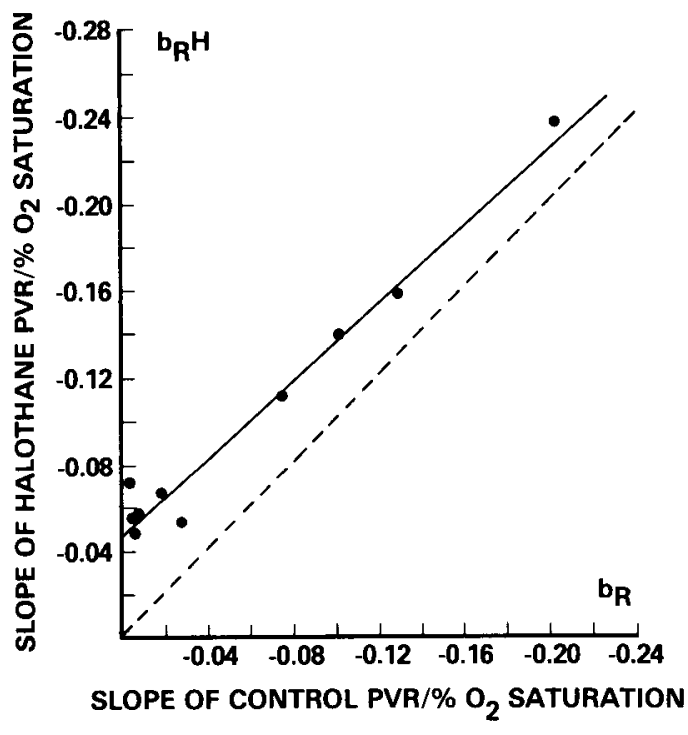

FIgURE 5 Slope of the halothane PVR response to hypoxia $\left(b_{R} H\right)$ against the slope of control hypoxic PVR response $\left(b_{R}\right)$ for each dog (data points). The solid line is the linear regression (see text) and the hatched line is the line of unity.

\section{Mean changes with halothane}

The uniqueness of the Ppa and PVR responses resulted in great variation between animals, so that group means showed little change and are mentioned here to allow comparison of the effects of halothane with halothane plus hypoxia.

Figure 6 shows mean values ( \pm 1 SD) for cardiac output, Ppa and PVR in the control group (open circles) at normoxia (C) and the pooled hypoxic values $(\mathrm{H})$, compared with the halothane group (closed circles). 

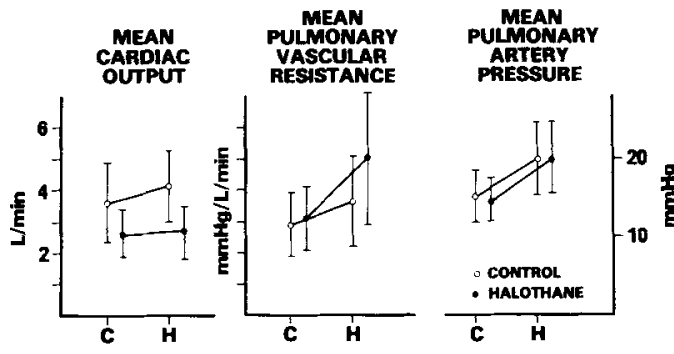

Figure 6 Mean normoxic $(\mathrm{C})$ and hypoxic $(\mathrm{H})$ values in controls (open circles) and after halothane (closed circles) \pm 1 SD for cardiac output, pulmonary vascular resistance and pulmonary artery pressure.

The mean cardiac output increased by 17 per cent with hypoxia, whereas induction with halothane caused an overall reduction in cardiac output of about 26 per cent and only a one per cent increase was obtained with hypoxia plus halothane. This contrasts with the mean PVR which increased by 21 per cent with hypoxia alone; and while only a small increase was found with halothane at normoxia, a highly significant increase of 42 per cent was found with halothane plus hypoxia. Mean Ppa increased to about the same extent ( 29 per cent) with both hypoxia alone and halothane plus hypoxia. A small reduction in Ppa $(6$ per cent occurred at normoxia with halothane, and persisted with halothane plus hypoxia. Halothane increased pulmonary wedge pressure (PWP) slightly in all dogs (mean increase $3 \mathrm{~mm} \mathrm{Hg}$ ). Thus, since Ppa was reduced, the net perfusion pressure was decreased. On the other hand, the decrease in cardiac output was much greater and resulted in a net increase in PVR at normoxia. Hypoxia did not further increase PWP or cardiac output during halothane exposure but since Ppa was increased, PVR was also increased. In summary then, halothane did not diminish the pressor response to any great extent but did abolish the cardiac response to hypoxia.

Figure 7 shows mean values for VD/VT ratio, arterial carbon dioxide tension and mixed expired carbon dioxide as a fractional concentration in the control (open circles) and halothane (closed circles) groups at normoxia (C) and hypoxia (H).

$\mathrm{VD}_{\mathrm{D}} / \mathrm{VT}_{\mathrm{T}}$ ratio increased with halothane at normoxia by about 9 per cent and decreased by 3 per cent during hypoxia plus halothane. In the control group $V_{D} / V_{T}$ ratio was reduced by about 8 per cent with hypoxia. Since VT was constant in these experiments, the se changes reflect changes in VD alone.

End-tidal carbon dioxide concentration as well as arterial and mixed venous carbon dioxide ten-

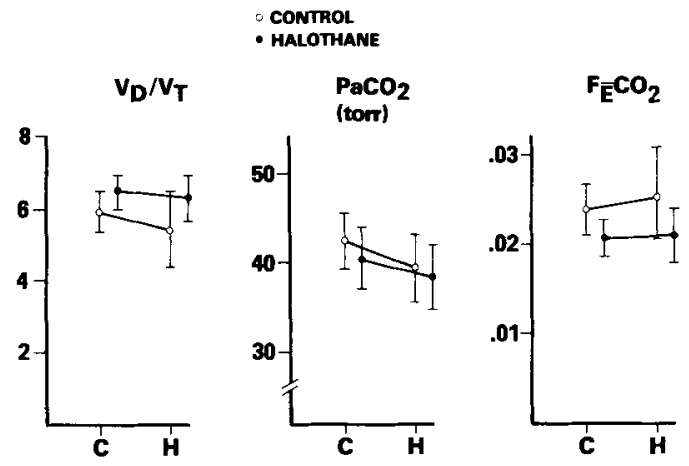

Flgure 7 Mean normoxic $(\mathrm{C})$ and hypoxic $(\mathrm{H})$ values in controls (open circles) and after halothane (closed circles) \pm 1 SD for dead space/tidal volume ratio $\left(\mathrm{VD} / \mathrm{VT}_{\mathrm{T}}\right.$ ), arterial $\mathrm{PCO}_{2}$ and mixed expired $\mathrm{CO}_{2}$ fraction.

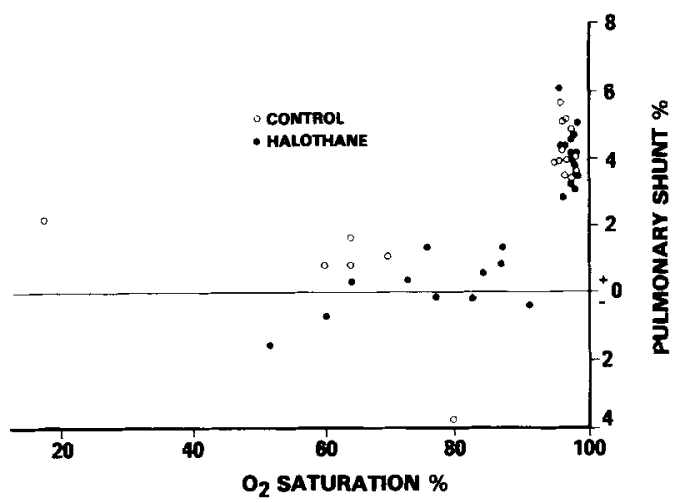

Figure 8 Pulmonary shunt flow fraction expressed as a percent of total blood flow for controls (open circles) and after halothane (closed circles) plotted against arterial $\mathrm{O}_{2}$ per cent saturation. The horizontal line is the line of the zero shunt.

sions decreased slightly with halothane at normoxia and were further decreased with hypoxia, but there was no significant difference in arterial carbon dioxide tension between the control and halothane groups.

The alveolar to arterial oxygen tension difference decreased with halothane exposure at normoxia, but this was not significant $(P=0.1)$; but a significant decrease occurred with halothane plus hypoxia, from 42.6 to $1.1 \mathrm{~mm} \mathrm{Hg}$. Little variation was found for alveolar to arterial oxygen tension difference between dogs.

\section{Pulmonary shunt fraction}

Figure 8 shows $\dot{Q} \mathrm{~s} / \dot{\mathrm{Q}} \mathrm{t}$ plotted against $\mathrm{Sa}_{\mathrm{O}_{2}}$ for each dog. Values of $\dot{Q} s / \dot{Q} t$ decreased exponentially in both control (open circles) and halothane (closed circles) groups. It can be seen from Figure 8 that halothane caused a small decrease in shunt 
fraction at equivalent levels of $\mathrm{Sa}_{\mathrm{O}_{2}}$. In five instances during halothane exposure this resulted in negative values for $\dot{Q} / \dot{Q} t$. due to the fact that mixed venous blood had a higher oxygen content than in alveoli at the end of five minutes of hypoxic breathing in these dogs. This could be interpreted as evidence that changes in shunt flow had not reached equilibrium after five minutes of halothane plus hypoxia exposure. However, our previous study ${ }^{4}$ has shown that negative $\dot{Q} s / \dot{Q} t$ and $\mathrm{P}(\mathrm{A}-\mathrm{a})_{\mathrm{O}_{2}}$ values are possible during equilibrium at low levels of hypoxic breathing in some animals, although in the present study these were only found after exposure to halothane.

\section{Discussion}

The variability of the pulmonary vascular response to alveolar hypoxia, whether expressed in terms of pulmonary vascular resistance (PVR) or pulmonary arterial pressure (Ppa), confirms our previous findings. ${ }^{4}$ As before, the inverse relationships of PVR and Ppa with arterial oxygen saturation were highly significant and reproduceable. Exposure to halothane and other inhalational anaesthetic agents has been shown in studies on isolated perfused lungs to reversibly depress this pressor response to hypoxia ${ }^{6,10-13}$ while in human subjects the response to unilaterial hypoxia is also depressed. 8 The constriction of pulmonary arterial vessels serving a region where alveolar hypoxia is present has been shown to divert pulmonary blood flow away from such regions to regions which are better oxygenated (higher alveolar oxygen tension), thereby minimizing arterial oxygen desaturation. ${ }^{14-16}$ If indeed inhalational anaesthetics depress this protective response, one might expect relatively more blood would flow to poorly ventilated or hypoxic regions in the lung and resulting arterial hypoxaemia.

There seems little doubt that in conditions of constant pulmonary blood flow in isolated lung studies in animals ${ }^{6}$ and in conditions of regional hypoxia in man, ${ }^{8}$ that halothane anaesthesia aggravates arterial oxygen desaturation through the mechanisms postulated above. However, in the intact animal subjected to whole lung hypoxia we found that the reduction in the pressor response is exceeded by the reduction in cardiac output, resulting in an increase in the PVR response at equivalent levels of arterial oxygen saturation. In these circumstances, then, the shift in PVR compared to arterial oxygen saturation increased rather than decreased the effectiveness of this protective mechanism. This is also indicated by our results for alveolar to arterial oxygen tension difference and pulmonary shunt fraction, which were slightly reduced on exposure to halothane at normoxia, but significantly reduced with hypoxia in the presence of halothane. These findings are surprising since it is generally accepted that the alveolar to arterial oxygen tension difference and pulmonary shunt fraction are increased during general anaesthesia. ${ }^{17,18}$ Various mechanisms have been suggested to explain the resulting hypoxaemia; altered lung recoil, airway closure, alveolar atelectasis, reduced functional residual capacity, and alveolar hypoxia. ${ }^{19,20}$ It seems unlikely that airway closure or alveolar atelectasis occurred in our preparation since all animals were artificially ventilated with IPPV and no progressive changes of arterial oxygen tension or saturation, or of airway pressures were found during control periods. However, dead space, which here included apparatus dead space, increased with exposure to halothane and accounted for the increase in $V_{D} / V_{T}$ ratio which we found, thus confirming early work in $\operatorname{man}^{21}$ and dogs. ${ }^{22}$ The alveolar component of physiological dead space will be increased during anaesthesia by any factor which reduces pulmonary blood flow or pressure. Inhalation of halothane resulted in a reduction of both cardiac output and pulmonary arterial pressure and it seems reasonable to assume that these account for the change in dead space. The reduction which we found for mixed expired carbon dioxide with halothane contrasts with the absence of any significant change in arterial carbon dioxide, indicating a possible disequilibrium state in terms of alveolar ventilation or alternatively altered carbon dioxide production.

The maintenance of arterial oxygen saturation in these circumstances could occur if there was only a small reduction in arterial oxygen tension or a shift in the oxygen/haemoglobin dissociation curve to the left, or both. We did find a small increase in arterial $\mathrm{pH}$ but little change in arterial oxygen tension on four exposures to halothane.

An increase in PVR with whole lung alveolar hypoxia would redistribute pulmonary blood flow to areas of higher alveolar oxygen only if the magnitude of the pressor response varied with the regional alveolar oxygen tension. Maloney and co-workers ${ }^{23}$ have shown that such a mechanism exists in sheep, so that areas normally receiving the bulk of pulmonary blood flow show the greatest rise in Ppa and PVR with hypoxia. Further, these areas are those which normally 
have the lowest alveolar oxygen tension. Our results suggest a similar mechanism exists in the dog.

The lack of any change in the increase in Ppa with hypoxia on exposure to halothane contrasts with studies in isolated lungs ${ }^{6.7}$ and humans. ${ }^{5}$ We did find a reduction in the absolute values of Ppa at all levels of hypoxia plus halothane compared to hypoxia alone, but the pressor response was not abolished or significantly attenuated by halothane. The anaesthetic concentrations used were similar and were calculated to achieve a $M A C$ value of one. It is possible that these reflect species differences; however, a more likely reason in our view is that the significant reduction in cardiac output we found resulted in augmentation of the hypoxic responses. It has recently been shown in dogs that increased pulmonary blood flow during dextran infusion results in blunting of the hypoxic pressor response ${ }^{24}$ and the converse would seem equally true, namely that reduced pulmonary blood flow would result in increase of the hypoxic pressor response.

Such a mechanism would require that the blunted hypoxic pressor response seen in isolated lungs during halothane exposure ${ }^{6,7}$ at constant blood flow could be recovered by lowering cardiac output. Further studies are required to clarify the exact role of halothane in these circumstances. It is of interest that the infusion of calcium after multiple halothane and hypoxic exposures did not alter the baseline PVR or its response to hypoxia, indicating that excitationcoupling was not diminished. This lends further weight to the hypothesis proposed that the haemodynamic factors may be an important determinant of the in vivo pulmonary vascular response to alveolar hypoxia.

\section{SUMMARY}

The pulmonary vascular response to alveolar hypoxia with and without halothane exposure was measured in dogs. Hypoxia increased pulmonary artery pressure (Ppa) and pulmonary vascular resistance (PVR) so that in each case inverse linear relationships were found with arterial oxygen saturation. These responses were highly significant and reproduceable but varied greatly between individuals. Halothane administration resulted in an increased slope of PVR against oxygen saturation due to the fact that reduction in cardiac output exceeded the reduction in Ppa. An analysis of variance showed that it was possible to predict accurately the hypoxic
PVR and Ppa responses under halothane anaesthesia from the control hypoxic responses. Anjmals with low PVR responses showed the greatest arterial oxygen desaturation with hypoxia, whereas high responders showed least oxygen desaturation. Thus it was possible to predict those individuals at risk from severe arterial oxygen desaturation under halothane anaesthesia.

\section{RÉSUMÉ}

La réponse vasculaire pulmonaire à l'hypoxie alvéolaire seule et pendant l'exposition à l'halothane a été mesurée chez des chiens. L’hypoxie a augmenté la pression artérielle pulmonaire et la résistance vasculaire pulmonaire selon une relation linéaire inverse à la saturation du sang artériel en oxygène. Les réponses étaient très significatives et reproductibles mais variaient beaucoup d'un individu à un autre. L'administration d'halothane augmentait la pente de la résistance vasculaire pulmonaire en fonction de la saturation en oxygène, ceci à cause d'une réduction plus grande du débit cardiaque que de la pression de l'artère pulmonaire. Une analyse de variation a montré qu'il était possible de prédire précisément les changements de la résistance vasculaire pulmonaire et de la pression artérielle pulmonaire sous anesthésie à l'halothane à partir des réponses à l'hypoxie seule. Les animaux chez lesquels la résistance pulmonaire répondait peu à l'hypoxie présentajent le plus haut degré de désaturation en oxygène, alors que ceux qui répondaient le plus à l'hypoxie montraient des désaturations moindres en oxygène. Il devenait possible de connaître les individus présentant un risque de désaturation artérielle sévère sous anesthésie àl'halothane.

\section{ACKNOWLEDGEMENTS}

The authors gratefully acknowledge the assistance of the Department of Biostatistics and Epidemiology, McMaster University, for statistical analysis, and to Miss Joyce Brandsen for typing the manuscript.

\section{REFERENCES}

1. Don, H.F., Wahba, W.M., \& Craig, D.B. Airway closure, gas trapping and the functional residual capacity during anaesthesia. Anesthesiology 36: 533-539(1972).

2. WEST, J.B. Blood flow to the lung and gas exchange. Anesthesiology 41:124-138(1974). 
3. HaUge, A. Hypoxic and pulmonary vascular resistance. The relative effects of pulmonary arterial and alveolar $\mathrm{PO}_{2}$. Acta Physiol. Scand. 76: 121-131 (1969).

4. Forrest, J.B. \& Babjak, A.F. Variability of the pulmonary vascular response to hypoxia and relation to gas exchange in dogs. Can. Anaesth. Soc. J. 25: 479-487 (1978).

5. Buertnaes, A., Hauge, A., Nakken, K.F., \& BREDESEN, J.E. Hypoxic pulmonary vasoconstriction: inhibition due to anaesthesia. Acta Physiol. Scand. 96: 283-285 (1976).

6. Loh, L., SEed, R.F., \& Sykes, M.K. The cardiorespiratory effects of halothane, trichloroethylene and nitrous oxide on the dog. Brit. J. Anaesth. 45: 125 (1973).

7. Sykes, M.K., Davies, D.M., \& Chakrabarti, M.K. The effects of halothane, trichloroethylene and ether on the hypoxic pressor response and pulmonary vascular resistance in the isolated perfused cat lung. Brit. J. Anaesth. 45: (2), 655-665 (1973).

8. BenUmof, J.L. \& Wahrenbrock, E.A. Local effects of anaesthetics on regional hypoxic pulmonary vasoconstriction. Anesthesiology, 43 (5), 525-532, 1975.

9. Rossing, R.G. \& CAIN, S.M. A nomogram relating $\mathrm{PO}_{2}, \mathrm{pH}$, temperature and haemoglobin saturation in the dog. J. Appl. Physiol. 21: 195-201 (1966).

10. Sykes, M.K., Davies, D.M., Loh, L., JasTRzebski, J., \& ShakrabarTi, M.K. The effects of methoxyflurane on pulmonary vascular resistance and hypoxic pulmonary vasoconstriction in the isolated perfused cat lung. Brit. J. Anaesth. 48: 191 (1976).

11. Hurtig, J.B., Tait, A.R., \& Sykes, M.K. Reduction of hypoxic pulmonary vasoconstriction by diethyl ether in the isolated perfused cat lung: The effect of acidosis and alkalosis. Can. Anaesth. Soc. J. 24 : 433-444 (1977).

12. Hurtig, J.B., Tait, A.R., Loh, L., \& Sykes, M.K. Reduction of hypoxic pulmonary vasoconstriction by nitrous oxide administration in the isolated perfused cat lung. Can. Anaesth. Soc. J. 24: 540-549 (1977).

13. SyKes, M.K., ARNot, R.N., JASTRZEBSKI, J.,
Gibbs, J.M., Obdrzalek, J., \& Hurtig, J.B. Reduction of hypoxic pulmonary vasoconstriction during trichloroethylene anaesthesia. J. Appl. Physiol. 39: 103 (1975).

14. Arborelius, M. \& Lilja, B. Effeets of hypoxic on the distribution of pulmonary blood flow in man. Bull. Physiopathol. Resp. 11:131p (1975).

15. Fowler, K.T. \& READ, J. Effect of alveolar hypoxia on zonal distribution of pulmonary blood flow. J. Appl. Physiol. 18:244 (1963).

16. Defares, J.G., Lundin, G., Arborelius, M., Stromblad, R., \& Svanberg, L. Effect of unilateral hypoxia on pulmonary blood flow distribution in normal subjects. J. Appl. Physiol. 15: 169 (1960).

17. Bendixen, H.H., Hedley-Whyte, J., \& Laver, M.B. Impaired oxygenation in surgical patients during general anaesthesia with controlled ventilation. New Engl. J. Med. 269: 991 (1963).

18. NunN, J.F. Applied Respiratory Physiology. 1st ed.. London, Butterworth, p. 219 et seq (1969).

19. Hickey, R.F., Visick, W.D., Fairley, H.B., \& FourCADE, H.E. Effects of halothane anaesthesia on functional residual capacity and alveolar arterial oxygen tension difference. Anesthesiology 38: 20 (1973).

20. Rehder, K., Sessler, A.D., \& Marsh, H.M. General anaesthesia and the lung. Am. Rev. Resp. Dis. /12: 541 (1975).

21. NunN, J.F., \& Hill, D.W. Respiratory dead space and arterial to end tidal $\mathrm{CO}_{2}$ tension difference in anaesthetized man. J. Appl. Physiol. I5: 383 (1960).

22. Severinghaus, J.W. \& Stupfel, M. Alveolar dead space as an index of distribution of blood flow in pulmonary capillaries. J. Appl. Physiol. 10: 335-348 (1957).

23. Maloney, J.E., Alcorn, D.. Cannata, J., WALKER, A., \& RitchiE, B.C. Regional vascular response to hypoxia in the lungs of anaesthetized sheep. Austral. J. Exp. Biol. Med. Sci. 52: 801-812 (1974).

24. Benumof, J.L. \& Wahrenbrock, E.A. Blunted hypoxic pulmonary vasoconstriction by increased lung vascular pressures. J. Appl. Physiol. 38: 846-850 (1975). 